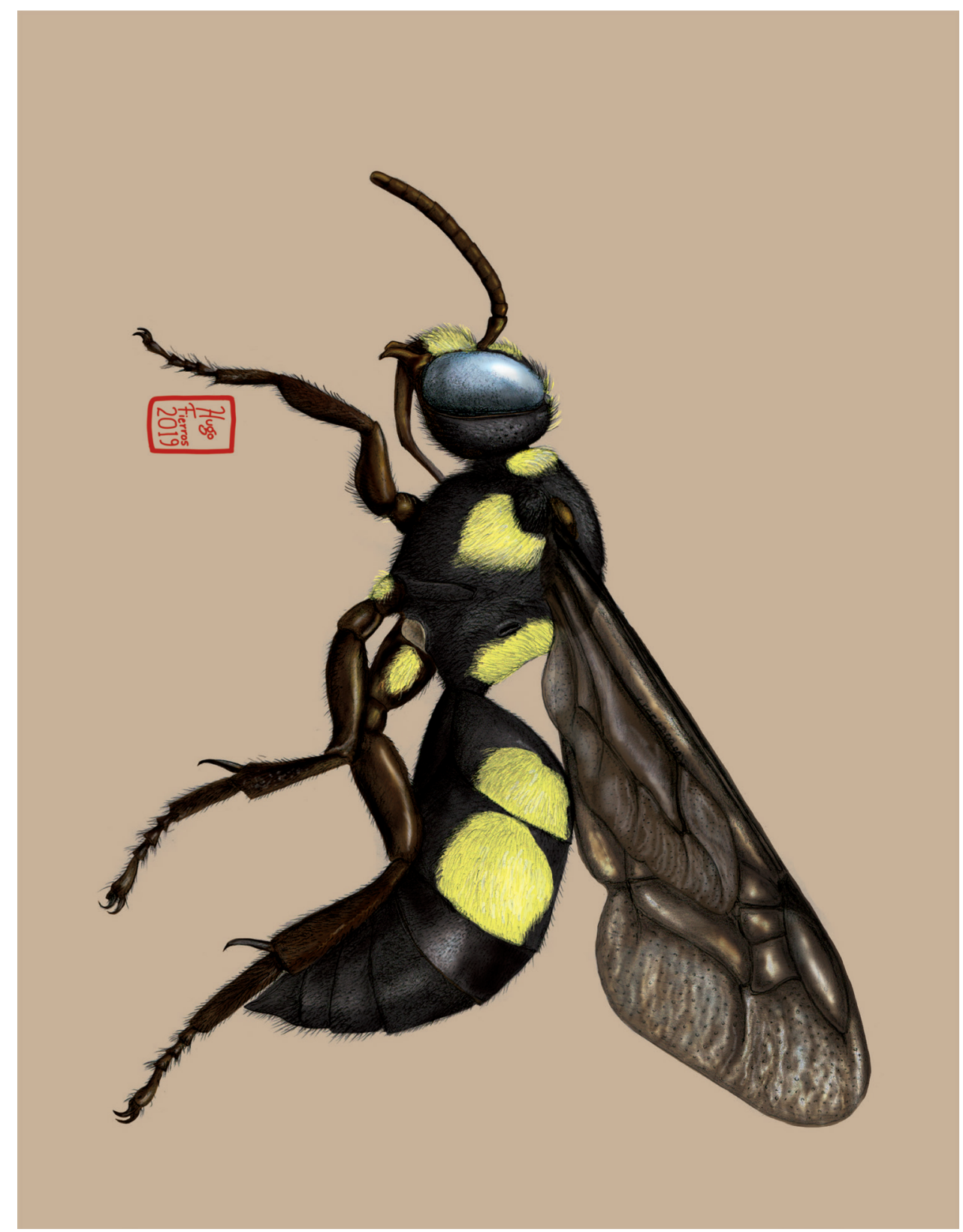

Dugesiana, Año 27, No. 1, enero 2020-junio 2020 (primer semestre de 2020), es una publicación semestral, editada por la Universidad de Guadalajara, a través del Centro de Estudios en Zoología, por el Centro Universitario de Ciencias Biológicas y Agropecuarias. Camino Ramón Padilla Sánchez \# 2100, Nextipac, Zapopan, Jalisco, Tel. 37771150 ext. 33218, http://148.202.248.171/dugesiana/index.php/DUG/index, glenusmx@gmail.com. Editor responsable: José Luis Navarrete-Heredia. Reserva de Derechos al Uso Exclusivo 04-2009-062310115100-203, ISSN: 2007-9133, otorgados por el Instituto Nacional del Derecho de Autor. Responsable de la última actualización de este número: José Luis Navarrete-Heredia, Editor y Ana Laura González-Hernández, Asistente Editorial. Fecha de la última modificación 1 de enero 2020, con un tiraje de un ejemplar.

Las opiniones expresadas por los autores no necesariamente reflejan la postura del editor de la publicación.

Queda estrictamente prohibida la reproducción total o parcial de los contenidos e imágenes de la publicación sin previa autorización de la Universidad de Guadalajara. 


\section{Los Odonata (Insecta) en la entomofilatelia}

\section{The Odonata (Insecta) in entomophilately}

\section{Juan Antonio López-Díaz y Benigno Gómez ${ }^{2}$}

${ }^{1}$ Instituto de Ciencias Biológicas, Universidad de Ciencias y Artes de Chiapas, Tuxtla Gutiérrez, Chipas, México. ${ }^{2}$ Departamento de Conservación de la Biodiversidad; El Colegio de la Frontera Sur. San Cristóbal de Las Casas, Chiapas, México. ${ }^{*}$ juanlodi44@gmail.com; ${ }^{2}$ bgomez@ecosur.mx

\section{RESUMEN}

Se presenta una revisión mundial del inventario de sellos postales con la representación de libélulas y caballitos del diablo (Insecta: Odonata) como organismos biológicos. Para ello se realizó una búsqueda exhaustiva en literatura especializada en entomofilatelia, además del uso de la internet. Se encontraron 426 sellos emitidos por 113 países, además de 102 documentos postales (matasellos, sobres del primer día, hojas suvenir). El primer registro de un Odonata en una estampilla postal la realiza Japón en 1923, mientras que los años 2000, 2011 y 2013 se destacan al emitirse la mayor cantidad de sellos con estos insectos. Taxonómicamente, se registra un total de 182 especies, que representa el 3.06\% de las especies reconocidas para el orden. De los sellos emitidos, el $6.59 \%$ representa especies en alguna categoría de riesgo con base a la IUCN.

Palabras clave: entomología cultural, sello postal, lista roja.

A global review of the postage stamp inventory is presented with the representation of dragonflies and damselflies (Insecta: Odonata) as biological organisms. To this end, an exhaustive search was carried out in literature specialized in entomophilately, in addition to the use of the internet. 426 stamps issued by 113 countries were found, in addition to 102 postal documents (postmarks, first day envelopes, souvenir sheets). The first record of an Odonata in a postage stamp is made by Japan in 1923, while the years 2000,2011 and 2013 stand out when emitting the greatest number of stamps with these insects. Taxonomically, a total of 182 species is recorded, representing $3.06 \%$ of the species recognized for the order. Of the stamps issued, $6.59 \%$ represent species in some risk category based on the IUCN.

Key words: cultural entomology, postage stamp, red list.

La filatelia se define como el pasatiempo de coleccionar y estudiar sellos postales y otros documentos relacionados a ellos. Debido al bajo costo y fácil adquisición de los sellos, la filatelia representa una vía importante de difusión cultural y científica (Ferreira 2006, Welker 2010), aunado a que puede representar un recurso didáctico importante en distintos niveles educativos (Zagkotas y Niaoustas 2019), por ejemplo, partiendo de la enseñanza en ciencias determinadas como la biología (Calver et al. 2011), o bien, impartiendo una disciplina tan especializada de esta ciencia como la entomología (Turienzo 2018).

Los insectos han influido en la vida del hombre y su cultura a través del tiempo, esto gracias a sus propiedades curativas y alimenticias, su comportamiento, rareza, belleza, e incluso su fealdad (Hogue 1987). La filatelia y la entomología son dos campos multifacéticos de estudio que unidos pueden llamarse "entomofilatelia" (Gómez y Junghans 2002) y se define como la afición por coleccionar sellos, timbres o estampillas postales con imágenes alusivas a insectos y en general sobre artrópodos (Hamel 1990). En la entomofilatelia se han representado desde insectos considerados plaga, como algunas especies de cucarachas, tales como Periplaneta americana Linnaeus, 1758 y P. australasiae Fabricius, 1775 (Gómez et al. 2015); insectos vectores, como los mosquitos del género Anopheles (Gerson 1981), hasta aquellos insectos altamente reverenciados, como las abejas domésticas (Apis sp.) por su producción de miel y su valor como polinizadoras (Pollock 2000), o que por su colorido y talla considerable, como es el caso de las mariposas y los escarabajos, les permita ser los órdenes mejor representados dentro de los sellos postales (Smith 1954, Moucha 1962, Hamel 1990, Costa-Neto 2002, Gómez y Junghans 2002, Reyes y Núñez 2008, Palacios-Vargas 2011).

El orden Odonata Fabricius, 1793 constituye un grupo de insectos acuáticos con alrededor de 6 mil especies en todo el mundo, distribuidas en tres subórdenes: 1) Zygoptera o caballitos del diablo, 2) Anisoptera o libélulas propiamente dichas y 3) Anisozygoptera, grupo relicto con características intermedias entre los dos subórdenes previos. Los odonatos habitan cuerpos de agua dulce y su mayor diversidad se encuentra en las regiones cálidas del planeta (Kalkman et al. 2008). Además, representan a uno de los grupos de insectos más antiguos, con registros desde el Pérmico (Grimaldi y Engel 2005), e incluyen al insecto más grande que ha vivido en el planeta, Meganeuropsis permiana Carpenter, 1939, cuya envergadura alar era de $70 \mathrm{~cm}$ (Dijkstra et al. 2013). 
El tema de los odonatos se ha integrado en múltiples facetas culturales, y su vez se han empleado diferentes vías para representarlos, que van desde sus nombres vernáculos, mitos, creencias y simbolismos, música y artes plásticas, literatura, poesía (Lara-Vázquez y Villeda-Callejas 2002) hasta integrarlos en algunas actividades como la "cacería de dragones" (dragon hunting), considerada como una forma de turismo con los odonatos y que estimula la investigación y la concientización en cuanto a medidas de tolerancia, el respeto y los impactos mínimos para estos insectos (Lemelin 2009). Los Odonata no han sido ajenos a su representación dentro de los sellos postales (Lara-Vázquez y Villeda-Callejas 2000), tal y como lo demostró Dennis R. Hamel hace casi tres décadas (1990), ocupando el sexto lugar en cuanto a órdenes de insectos mejor representados. El objetivo del presente estudio fue realizar un inventario de sellos postales con imágenes impresas de odonatos como organismos biológicos, analizar las causas de dicha representación y hacer énfasis en la conservación de estos organismos.

\section{MATERIAL Y MÉTODOS}

Se realizó una revisión documental de sellos, así como de otros documentos postales (matasellos, sobres del primer día, hojas suvenir), emitidos hasta mayo de 2018 en las que estuvieran impresas imágenes de odonatos como organismos biológicos. Para ello se consultó el Catálogo Domfil de mariposas y otros insectos (Domingo 1997), el Atlas de sellos de insectos en el mundo (Hamel 1991), la revisión de insectos para Cuba (Reyes y Núñez 2008), las consideraciones generales de Costa-Neto (2002) y Palacios-Vargas y Navarrete-Heredia (2002), además de una búsqueda exhaustiva en la internet (Entomofilatelia del Museo de la Universidad Autónoma de León [http://bio-nica.info/topic/ index.html], Entomophila [http://entomophila.chez.com], Insects on Stamps [www.asahi-net.or.jp/ CH2M-NITU/ indexe.htm], Odonata on Stamps [http://defworld.freeoda. com], Skap's Bug Stamps [http://skap.readyhosting.com/ country_master.html], Stampdile Limited [www.stampdile. com], Stamp World [www.stampworld.com], Worl Online Philatelic Agency [http://wopa-stamps.com]).

La información obtenida se concentró en una base de datos (Microsoft Access $($ ) ), incluyendo los siguientes campos de captura: 1) año, 2) país, 3) suborden, 4) superfamilia, 5) familia, 6) género, 7) especie válida, 8) categoría de riesgo de la Unión Internacional para la Conservación de

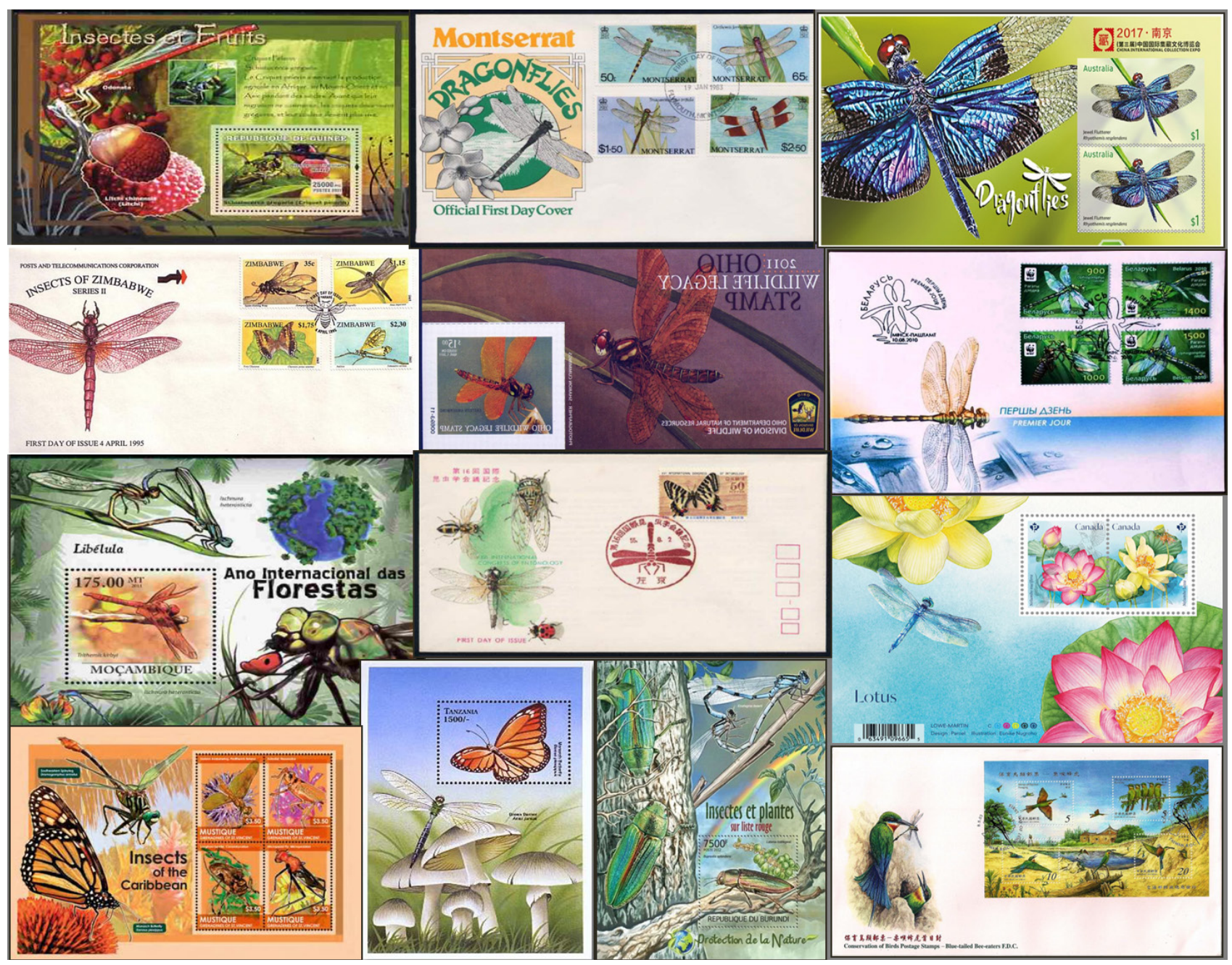

Figura 1. Algunos documentos postales con la ilustración de libélulas y caballitos del diablo. 
la Naturaleza o IUCN por sus siglas en inglés, y 9) observaciones. El arreglo taxonómico siguió la propuesta de Dijskstra et al. (2013), sin embargo, se consideraron los criterios de Garrison et al. (2006), al señalar que la familia Libellulidae (sensu lato) está integrada por las subfamilias Corduliinae, Macromiinae y Libellulinae.

\section{RESULTADOS}

Se encontró un total de 426 sellos emitidos por 113 países donde se ilustran a los odonatos como organismos biológicos. Asimismo, se registran 102 documentos postales (matasellos, sobres del primer día, hojas suvenir) con imágenes alusivas a estos artrópodos (Figura 1). De los sellos catalogados, taxonómicamente se identifica un total de 182 especies, que representa el $3.06 \%$ del total reconocido para estos insectos (Cuadros 1 y 2). No obstante, 24 sellos de 15 países (Australia[1], China[1], Corea del Norte[3], Corea del Sur[2], Estados Unidos[1], Finlandia[1], Irlanda[1], Japón[7], Moldavia[1], Rumania[1], Rusia[1], San Marino[1], Sierra Leona[1], Sudáfrica[1], Uganda[1]) carecen de elementos taxonómicos que permitan referirlos en alguna especie conocida.

Se ilustran especies para los tres subórdenes reconocidos de odonatos, con mayor proporción en Anisoptera (75.47\%) que Zygoptera (24.3\%), mientras que Anisozygoptera se representa únicamente en un sello emitido por Japón en 1986 con la especie Epiophlebia superstes Selys, 1889, que es una especie nativa de este país (Figura 2). Las familias mayormente representadas son Libellulidae, Aeshnidae, Coenagrionidae y Calopterygidae, que en conjunto representan más del $80 \%$ del total de sellos expuestos. Anax imperator Leach, 1815, Calopteryx splendens (Harris, 1780) y Anax partenophe (Selys, 1839) son las especies con el mayor registro de sellos (26, 11 y nueve, respectivamente).

Históricamente, Japón fue el primer país en representar un odonato, en 1923, en una serie de siete sellos con diferente denominación. El mayor número de registros se generó en el 2000 (45), 2011 (37) y 2013 (22) (Figura 3), mien- tras que Malasia, China, Japón y Vietnam constituyen los países con la mayor cantidad de estampillas, que en conjunto representan el $19.48 \%$ del total catalogado. Finalmente, se encontraron cuatro sellos con determinación taxonómica errónea expuestos por Bután en 1997, Granada-Granadinas y Micronesia en 2002, y Benín en 2008, así como un sello emitido por Lesoto en 2002 cuya especie (Cordulegaster boltonii Donovan, 1807) no tiene área de distribución en este país emisor (Figura 4).

\section{DISCUSIÓN}

Odonata representa a un orden de insectos ampliamente conocido a nivel mundial al plasmarse una fracción importante de especies del total existente en los sellos y otros

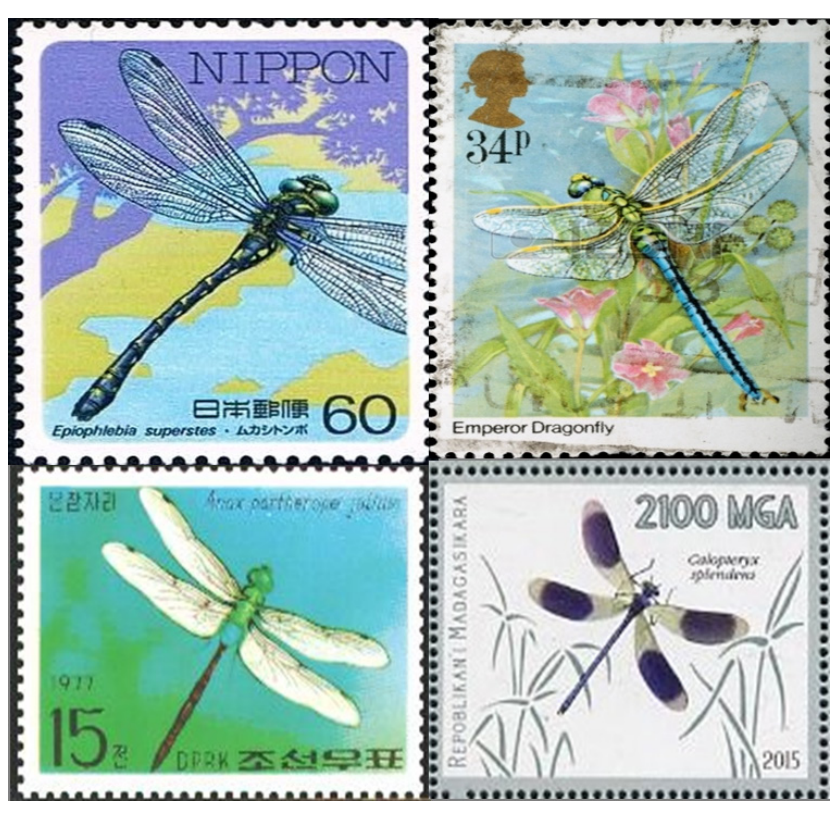

Figura 2. Especie de Anisozygoptera (superior izquierda), y especies más representadas en los sellos postales (superior derecha, inferior izquierda y derecha).

Cuadro 1. Taxonomía determinada en los sellos de Odonata.

\begin{tabular}{rccccc}
\hline & Suborden & Superfamilias & Familias & Géneros & Especies \\
\hline Total existente & 3 & 10 & 30 & 652 & 5952 \\
Total registrado & 3 & 10 & 15 & 82 & 182 \\
\hline
\end{tabular}

Cuadro 2. Proporción de sellos registrados con odonatos en relación a otros grupos de artrópodos.

\begin{tabular}{ccccc}
\hline & $\begin{array}{c}\text { Scarabaeoidea } \\
\text { Gómez y Junghans }\end{array}$ & $\begin{array}{c}\text { Blattodea } \\
\text { Gómez et al. } \\
2002\end{array}$ & $\begin{array}{c}\text { Scorpionida } \\
\text { Góm y Junghans }\end{array}$ & $\begin{array}{c}\text { Odonata } \\
\text { Este estu- } \\
\text { dio }\end{array}$ \\
\hline $\begin{array}{c}\text { Diversidad del grupo } \\
\text { (spp.) }\end{array}$ & 35000 & 4341 & 2231 & 5952 \\
Sellos registrados & 244 & 8 & 47 & 426 \\
Proporción (\%) & $0.7 \%$ & $0.18 \%$ & $2.11 \%$ & $7.16 \%$ \\
\hline
\end{tabular}




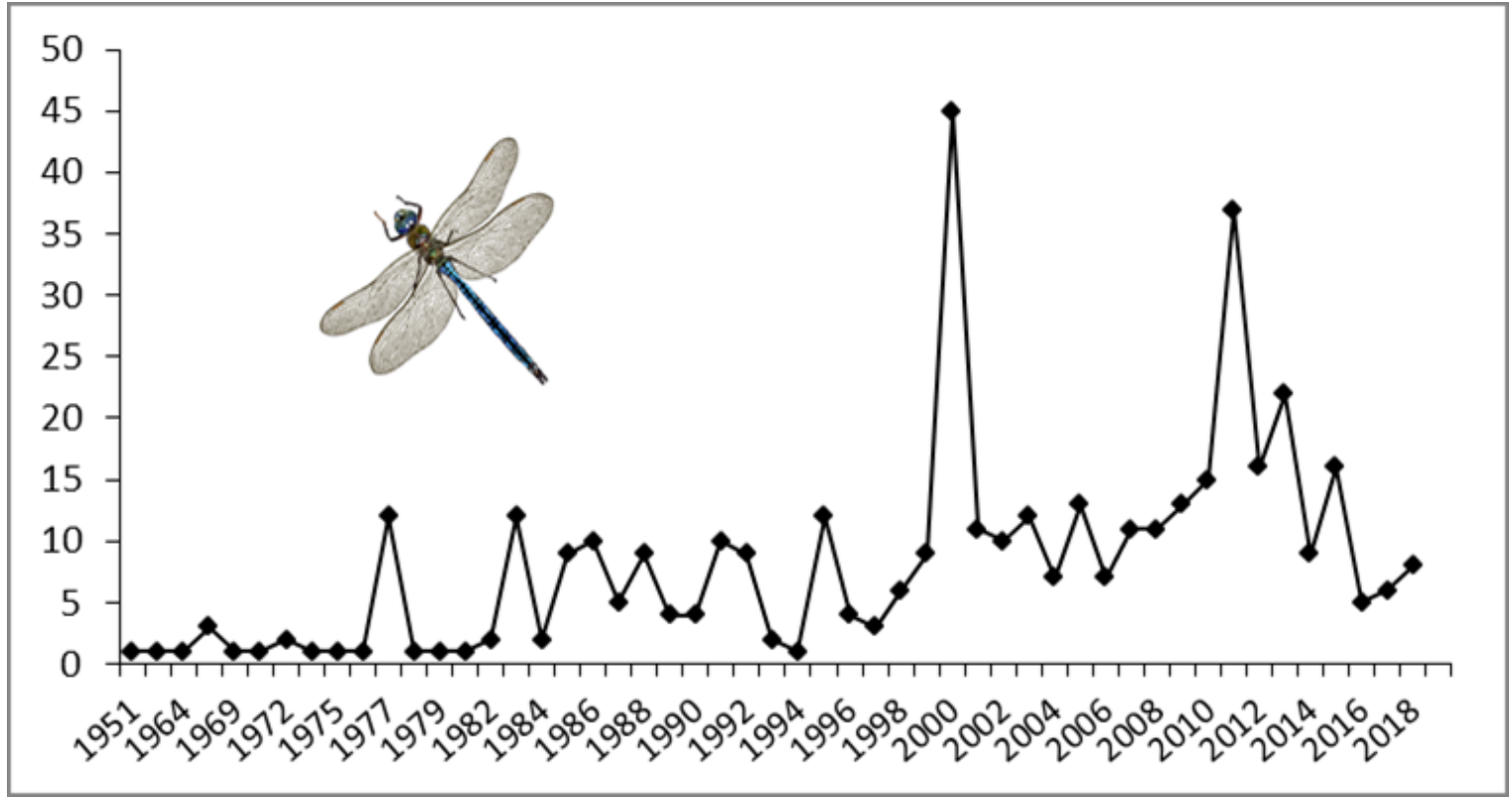

Figura 3. Registro histórico de sellos emitidos con ilustraciiones de odonatos.

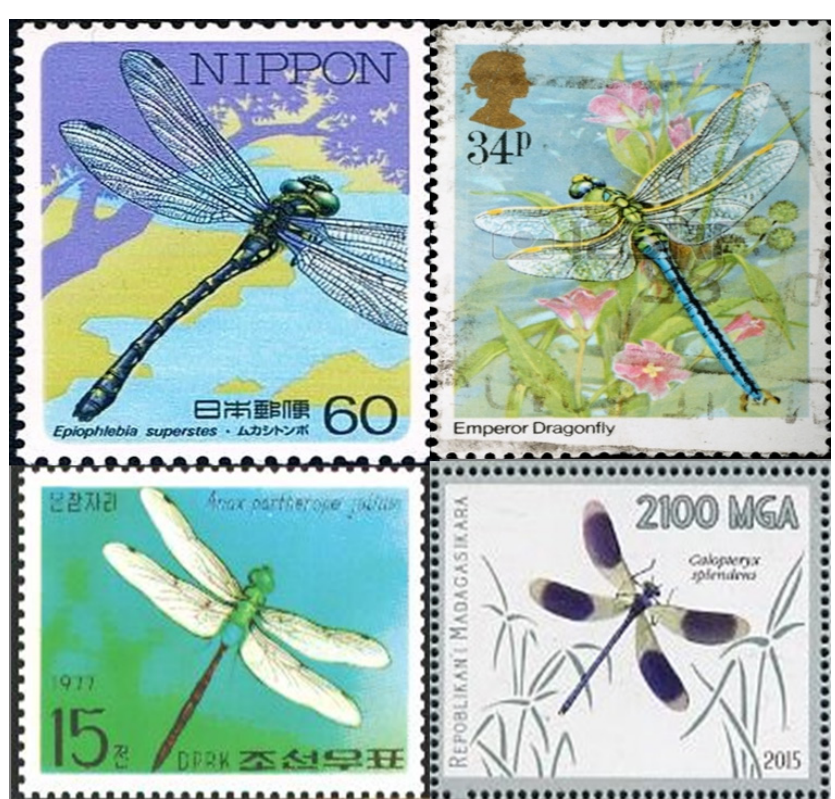

Figura 4. Estampillas postales con denominación incorrecta de especies.

documentos postales en más de 100 países. Estos resultados demuestran que posterior al inventario realizado por Hamel (1990), proporcionalmente por cada década transcurrida fue emitida alrededor de una centena de sellos con la representación de odonatos. Además, el porcentaje de sellos con respecto a la diversidad del orden a nivel mundial es mayor si se compara con otros grupos de artrópodos como el de los Mantodea (Hernández-Baltazar y Gómez, 2019), Scorpionida (Gómez y Junghans 2016), Blattodea (Gómez et al. 2015) y Scarabaeoidea (Gómez y Junghans 2002).

Taxonómicamente, el suborden Anisoptera es quien posee la mayor cantidad de sellos expuestos a través de las familias Libellulidae y Aeshnidae, lo cual no es extraño si se considera que Libellulidae representa a la familia de odonatos con mayor diversidad a nivel mundial, con alrededor de 1316 especies (Dijkstra et al. 2013); mientras que Aeshnidae integra a una familia de odonatos de gran tamaño, siendo esta la razón más probable de su representación dentro de los sellos postales. Zygoptera se encuentra mayormente representada a través de Coenagrionidae, la cual integra a la segunda familia con mayor diversidad a nivel mundial con 1267 especies (Dijskstra et al. 2013); por su lado, Calopterygidae quien también aporta una fracción considerable de sellos al suborden Zygoptera, representa a una familia con especies que poseen en su cuerpo un gran colorido, siendo quizás un atractivo para ser plasmadas dentro de los sellos.

Ocasionalmente, las imágenes de estampillas pueden desviarse de la cultura de su país de origen (Broadhead 2016), este es el caso del sello emitido por Lesoto en 2002, donde se representa a Cordulegaster boltonii, cuya distribución ha sido registrada desde el suroeste de Europa hasta el norte de África (Torralba-Burrial y Ocharan 2007), no así para Sudáfrica. Por otro lado, se encuentran sellos cuya leyenda no corresponde con la especie ilustrada, en este caso el sello emitido por Bután en 1997 con la denominación Agrion splendens (actualmente C. splendens) en lugar de A. imperator como lo demuestra la imagen; los sellos emitidos por Granada-Granadinas y Micronesia en 2002, ambos con la leyenda Anax junius (Drury, 1773) en lugar de Calopteryx virgo Linnaeus, 1758, tal y como se verifica en su imagen; asimismo, se encuentra una estampilla emitida por Benín en 2008 donde se ilustra probablemente a un Enallagma sp. y no a Aeshna caerulea (Ström, 1783) como fue designada.

Son diversas las causas por las cuales los insectos han conformado el tema principal dentro de los timbres pos- 


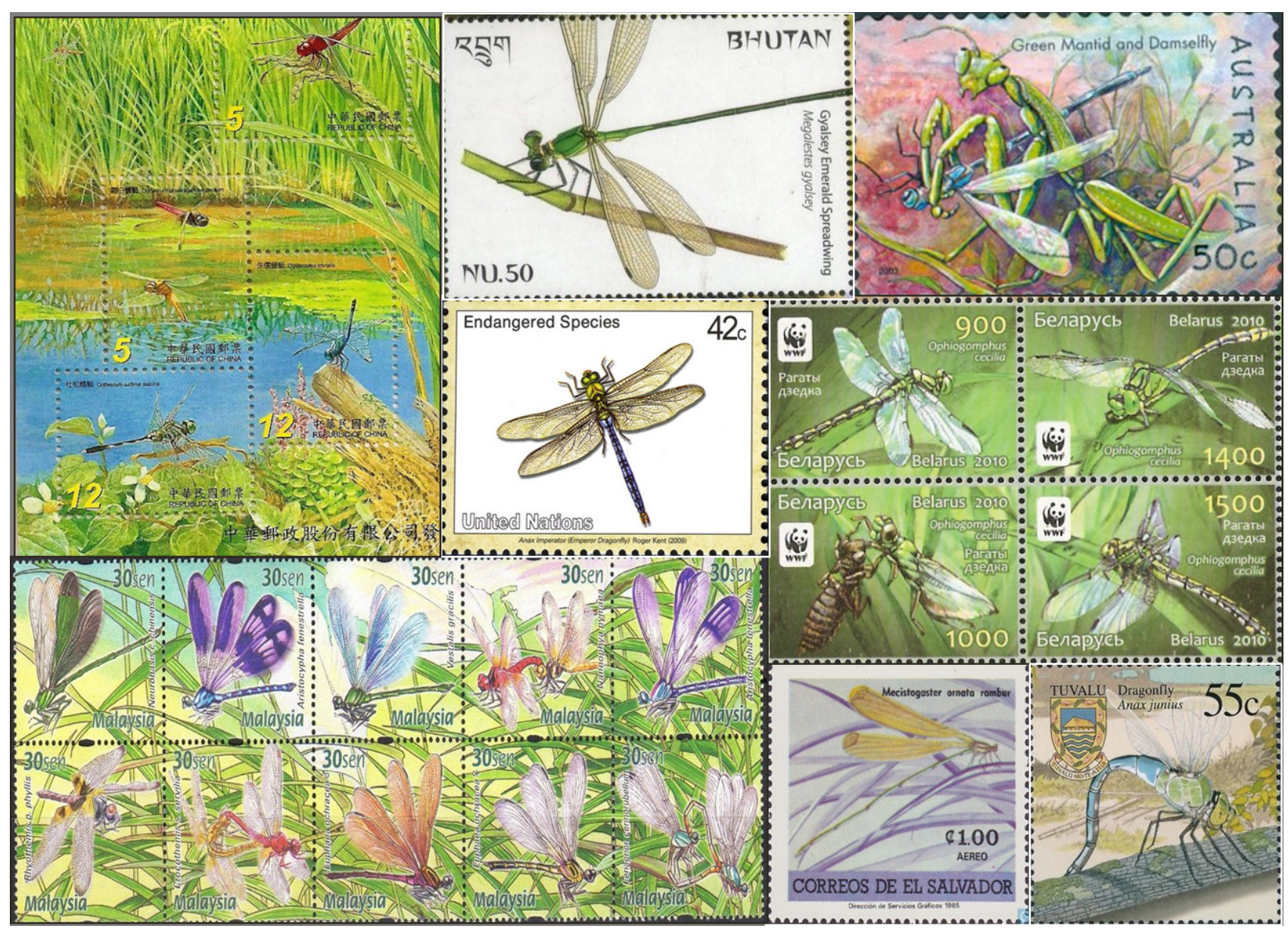

Figura 5. Algunos ejemplos de sellos emitidos con diferentes motivos.

tales (Pollock 2000). En este trabajo se considera que los Odonata han sido plasmados en estos documentos por los siguientes motivos:

Aspectos simbólicos: en varios países orientales la presencia de las libélulas y caballitos del diablo está relacionada a cosas positivas (buena suerte, buenos deseos) (Lara-Vázquez y Villeda-Callejas 2002). Para Japón estos artrópodos simbolizan el coraje, la fuerza, la victoria y la felicidad, por ello no es nada extraño que en 1923 este país ilustrara a estos insectos en sus timbres (Corbet 1999; Palacios-Vargas y Navarrete-Heredia 2002). Por su lado, China considera a los odonatos como benéficos y favorables probablemente debido a su abundancia en los campos de cultivo de arroz, alimento principal de su población (Inoue 1989), tal y como se puede apreciar en la planilla completa de sellos emitidos por este país en 2006 (Figura 5). Pese a que para algunos pueblos occidentales la percepción que se tiene hacia estos insectos está vinculada a seres mitológicos (demonios, duendes, brujas) y con ello a cuestiones negativas (mala suerte, calamidades, infortunios, desastres) (Lara-Vázquez y Villeda-Callejas 2002), los resultados de este trabajo indican que la tendencia ha ido cambiando en las últimas décadas, al determinar que países como San Vicente y las Granadinas, Estados Unidos, Santa Lucía, El Salvador y Filipinas han emitido una cantidad considerable (19.48\%) de sellos con estos organismos.

Aspectos físicos: refiriéndose al gran tamaño y/o al valor estético (colorido, forma, delicadeza) que pueden exhibir algunas especies de odonatos. Modelo de ello es $A$. imperator al representar la libélula más grande $(8 \mathrm{~cm}$ de longitud y una envergadura alar de $12 \mathrm{~cm}$ ) para varios países de África, Europa y Asia (Corbet 1957); esto mismo sucede con $A$. parthenope quien posee gran longitud corporal $(7 \mathrm{~cm}$ de longitud y una envergadura alar de $5 \mathrm{~cm}$ ) pero menor en comparación con A. imperator (Kalkman 2006), esta característica probablemente les ha permitido a ambas especies ocupar las dos primeras posiciones en cuanto a especies de Odonata ilustradas en los sellos postales. Existen algunos caballitos del diablo distribuidos en América que superan dichos tamaños, este es el caso de Mecistogaster ornata Rambur, 1842 con una longitud de hasta $10 \mathrm{~cm}$ y una envergadura alar de $12 \mathrm{~cm}$ (von Ellenrieder 2009), y que fue representada en un sello de El Salvador en 1985. Adicionalmente al tamaño, la mayoría de los Odonata poseen diversos colores en sus alas, sin embargo los de su cuerpo no pueden conservarse (Palacios-Vargas y Navarrete-Heredia 2002), es por ello que la entomofilatelia cobra un papel muy importante para plasmar diferentes patrones y diseños de especies como C. splendens, (una de las tres especies mayormente representadas), Aristocypha fenestrella 
Rambur, 1842; C. virgo; Celithemis eponina Drury, 1773; Ceriagrion cerinorubellum (Brauer, 1865); Libellula pulchella Drury, 1773; Neurobasis chinensis chinensis (Linnaeus, 1758); Neurothemis ramburii (Brauer, 1866); Orthemis ferruginea (Fabricius, 1775); Perythemis tenera Say, 1839; Phaon iridipenis (Burmeister, 1839), Plathemis lydia Drury, 1773; Rhyothemis graphiptera Rambur, 1842; $R$. obsolescens Kirby, 1889; R. princeps Kirby, 1894, R. variegata Linnaeus, 1763, Sympetrum pedemontanum (Müller in Allioni, 1766); y Trithemis aurora (Burmeister, 1839), tan solo por mencionar algunos ejemplos.

Aspectos bioecológicos: resaltando la historia natural y ecología del orden Odonata. Así se logra apreciar el dimorfismo sexual de especies como $C$. splendens y $C$. virgo en los sellos de Albania en 1966 y Sahara Occidental en 1995, respectivamente; esta misma distinción se observa en Crocothemis servilia servilia (Drury, 1773), Euphaea ochracea Selys, 1859, y N. chinensis chinensis en los timbres emitidos por Malasia en el 2000, así como para Libellula lydia Drury, 1773, L. pulchella, y Orthetrum sabina (Drury, 1773) en los sellos expuestos por Sudán del Sur. La metamorfosis es evidenciada por Bielorusia en 2010 en una serie de cuatro sellos donde se ilustra la exuvia de la náyade de Ophiogomphus cecilia (Geoffroy en Fourcroy, 1785), así como el teneral y varios adultos maduros de esta especie. Los odonatos también han sido figurados como parte de la cadena alimenticia, esta interacción se representa en el sello emitido por Australia en 2003 en el que se incluye a una Mantis religiosa Linnaeus, 1758 alimentándose del caballito del diablo Diphlebia nymphoides Tillyard, 1912; además, China en el 2006 ilustra al ave Merops philippinus Linnaeus, 1967, cazando a la libélula Orthetrum pruinosum neglectum Rambur, 1842. Por último, la migración y la alta capacidad de dispersión de ciertas especies de Anisoptera han sido quizá las causas por las cuales han sido objeto de su representación dentro de los sellos de varios países, así se tiene que Pantala flavescens (Fabricius, 1798) al integrar una especie migrante obligada, es conocida para todos los continentes atravesados por la línea ecuatorial, además de otras especies como A. junius (Boudot et al. 2016), o bien, que debido a la alta dispersión que tienen algunas especies son ilustradas en los sellos de varios países, ejemplo de ello son A. imperator y A. parthenope, la primera especie distribuida desde África, Europa, la península arábiga y en Asia suroccidental y central (Corbet 1957), mientras que la segunda está muy extendida en Europa, desde la Península Ibérica hasta Rusia, las islas más meridionales, Lituania y cuyo rango se extiende también a través de Asia y África, llegando a Japón, China y el Sahara (Kalkman 2006).

Biodiversidad: en este caso se expresa la variedad de especies de odonatos que existen en una región determinada y la inclusión de especies nuevas. Por ejemplo, Malasia en el 2000 evidenció en una hoja suvenir el número de especies (220) distribuidas en este país y exhibiendo esta diversidad en varias de sus estampillas. Asimismo, varios países (Escocia, Gales, Inglaterra, Irlanda del Norte, Jersey, Malasia,
Singapur, Viet Nam, entre otros) han emitido sellos con el tema "vida en el estanque" donde se ilustra la diversidad de organismos acuáticos conviviendo en este tipo de ecosistemas, entre ellos los Odonata. Bután en el 2018 emitió una estampilla con la ilustración de una especie de reciente descripción: Megalestes gyalsey Gyeltshen, Kalkman \& Orr, 2017.

Conservación: por último y no menos importante, se encuentran aquellas estampillas en las que se representan especies endémicas y/o en peligro de extinción, y por lo tanto se hace énfasis en su conservación. Los endemismos han sido evidentes para países como Japón en 1987, Nueva Zelanda en 1997 y Palaos en 1999, al exhibir sellos con la representación de Calopteryx cornelia Selys, 1853, Uropetala carovei (White, 1846) y Megalagrion leptodemas (Perkins, 1899), respectivamente. Es importante destacar los sellos emitidos por Estados Unidos y Suiza en 2009, ya que a través de la ONU emitieron una serie de estampillas con el tema "Especies en peligro", donde se ilustra a $A$. imperator para el primer país y a Coenagrion mercuriale (Charpentier, 1825) para el segundo; a ello se le suma España al emitir en 2015 una serie de cuatro estampillas con el tema "Especies protegidas", entre ellas la libélula Onychogomphus forcipatus (Linnaeus, 1758). Bielorrusia en 2010 y Finlandia en 2016 emitieron sellos con el logotipo del Fondo Mundial para la Naturaleza (WWF, por sus iniciales en inglés), quien hace un esfuerzo de representar a $O$. cecilia y Nehalennia speciosa (Charpentier, 1840) correspondientemente, ya que la primera especie se integra en el libro rojo de especies en peligro de extinción de Bielorrusia (Malikova 2009), mientras que la segunda especie se encuentra clasificada desde el 2006 en la categoría "casi amenazada" dentro de la lista roja de la IUCN (Bernard y Wildermuth 2006).

Del total de sellos emitidos 28 (6.59\%) contiene a una especie que actualmente se encuentra en alguna categoría de riesgo con base a la IUCN. Cuatro de estas especies está incluida en la categoría "casi amenazada" [Cordulegaster bidentata Selys, 1843; C. mercuriale; Mortonagrion hirosei Asahina, 1972; Nehalennia speciosa (Charpentier, 1840)], dos en la categoría "vulnerable" [Chlorolestes elegans Pinhey, 1950; Megalagrion oahuense (Blackburn, 1884)], tres "en peligro crítico" [Boninthemis insularis Matsumura, 1913; M. leptodemas; Enallagma maldivensis Laidlaw, 1902] y una "en peligro de extinción" [Petalura pulcherrima Tillyard, 1913].

Sin duda, la educación es la base para la toma de conciencia sobre la problemática de la crisis de la biodiversidad y para el logro de un cambio de conducta a nivel individual y comunitario (Gómez y Junghans 2002). En este sentido, la filatelia al ser uno de los pasatiempos más inclusivos en el mundo (Broadhead 2016), juega un papel importante como medio de difusión cultural y científico (Ferreira 2006) y su utilidad como recurso didáctico ha sido probado en diferentes materias y niveles educativos (Turienzo 2018, Calver et al. 2011, Zagkotas y Niaoustas 2019). La entomofilatelia representa una importante vía de promoción para la 
conservación de los Odonata, ya que en los sellos postales se ilustran especies cuya distribución es muy lejana o que están próximas a extinguirse (Turienzo y Alves Carneiro 2017), como ha sido documentado en el presente estudio, y que independientemente del motivo de su representación dentro de los sellos, probablemente se hace un esfuerzo de concientización con respecto a la preservación del hábitat de estos insectos, ya que como larvas o adultos existen varias especies de odonatos que son altamente sensibles ante las modificaciones en el biotopo, y por ello, son considerados excelentes bioindicadores de la calidad ambiental (Bulánková 1997, Monteiro-Júnior et al. 2015).

\section{LITERATURA CITADA}

Bernard, R. y H. Wildermuth. 2006. Nehalennia speciosa. The IUCN Red List of Threatened Species. Disponible en: http://dx.doi.org/10.2305/IUCN.UK.2006.RLTS. T60265A12336089. Fecha de consulta: 03 de marzo de 2019.

Boudot, J.-P., V. Clausnitzer, B. Samraoui, F. Suhling, K.D.B. Dijkstra, W. Schneider and D.R. Paulson. 2016. Pantala flavescens. e.T59971A65818523. Disponible en: http://dx.doi.org/10.2305/IUCN.UK.2016-3.RLTS. T59971A65818523. Fecha de consulta: 22 de octubre de 2018.

Broadhead, T.W. 2016. The culture of stamps: cultural touchstones are vital to a stamp's purpose. American Philatelist, 1110-1118.

Bulánková, E. 1997. Dragonflies (Odonata) as bioindicators. Biologia, Bratislava. 52(2), 177-180.

Calver, M., K. Addison y J. Annan. 2011. Postage Stamps as Teaching Aids in Biology. The American Biology Teacher, 73(5): 289-290.

Corbet, P.S. 1957. The Life-History of the Emperor Dragonfly Anax imperator Leach (Odonata: Aeshnidae). Journal of Animal Ecology, 26: 1-69.

Corbet, P.S. 1999. Dragonflies: behavior and ecology of Odonata. Cornell University Press, New York.

Costa-Neto, E.M. 2002. Entomofilatelia: os insetos na arte filatélica. Bioikos, 16(1/2): 61-67.

Dijkstra, K-D.B., G. Bechly, S. Bybee, R. Dow, H. Dumont, G. Fleck, R. Garrison, M. Hämäläinen, V. Kalkman, H. Karube, M. May, A. Orr, D. Paulson, A. Rehn, G. Theischinger, J. Trueman, J. Tol, N. von Ellenrieder and J. Ware. 2013. The classification and diversity of dragonflies and damselflies (Odonata). Zootaxa, 3703: 36-45.

Domingo, J. 1997. Catálogo de sellos temáticos Fauna, Mariposas y otros Insectos. Ediciones Domfil. Sabadell, España.

Ferreira, L.E. 2006. A Certain Look at Philately. Edições Húmus Lda. Braga, Portugal.

Garrison, R.W., N. von Ellenrieder and J.A. Louton. 2006. Dragonfly Genera of the New World: an illustrated and annotated key to the Anisoptera. The Johns Hopkins University Press. Maryland, United States of America.
Gerson, J.S. 1981. Malaria Philatelist. Quarterly Journal of Malaria Philatelists International, 2: 1-16.

Gómez, B. y C. Junghans. 2002. Los Scarabaeoidea (Insecta: Coleoptera) en la filatelia. Cuadernos de Biodiversidad, 11: 10-14.

Gómez, B. y C. Junghans. 2016. Los alacranes (Arachnida: Scorpionida) en la filatelia. Dugesiana, 23(1): 37-43.

Gómez, B., M.R. Domínguez y C. Junghans. 2015. Las cucarachas (Blattodea) representadas en los sellos postales (entomofilatelia). (pp.77-82). En: Castaño-Meneses, G. y J.L. Navarrete-Heredia (Eds.). Avances en la entomología cultural mexicana. UNAM-CUCBA-Universidad de Guadalajara.

Grimaldi, D. y M.S. Engel. 2005. Evolution of the Insects. Cambridge University press, New York.

Hamel, D.R. 1990. Insects on stamps. American Entomologist, 36(4): 273-281.

Hamel, D.R. 1991. Atlas of Insects on Stamps of the World. Tico Press, Falls Church. Virginia, Estados Unidos.

Hernández-Baltazar, E. y B. Gómez. 2019. Los Mantodea en la filatelia (Insecta: Dictyoptera). Dugesiana, 26(2): 71-76.

Hogue, L.C. 1987. Cultural entomology. Annual Review of Entomology, 32:181-199

Inoue, S. 1989. Dragonfly folklore in Haiku. Review of research and inquires Kinran Tankidaigaku, 20:157187.

Kalkman, V.J. 2006. Anax parthenope (Selys, 1839) Lesser Emperor. (pp.168-169). In: Dijkstra K.-D.B. (Ed.). Field Guide to the dragonflies of Britain and Europe. British Wildlife Publishing, Milton Stour, Inglaterra.

Kalkman, V., V. Clausnitzer, K. Dijkstra, A. Orr, D. Paulson and J. Tol. 2008. Global diversity of dragonflies (Odonata) in freshwater. Hydrobiologia, 595: 351-363.

Lara-Vázquez, J.A. y M.P. Villeda-Callejas. 2000. Libélulas: esos ágiles cazadores. Revista Chapingo Serie Ciencias Forestales y del Ambiente, 6: 55-61.

Lara-Vázquez, J.A. y M.P. Villeda-Callejas. 2002. Odonatos en la manifestación cultural de los pueblos. Revista Chapingo Serie Ciencias Forestales y del Ambiente, 8(2): 119-124.

Lemelin, H. 2009. Goodwill hunting: dragon hunters, dragonflies and leisure. Current Issues in Tourism, 12(3): 235-253.

Malikova, E. 2009. Ophiogomphus cecilia. The IUCN Red List of Threatened Species. Disponible en: http://dx.doi.org/10.2305/IUCN.UK.2009-2.RLTS. T15364A4525058. Fecha de consulta: 03 de marzo de 2019.

Monteiro-Júnior, C.D.S.M., L. Juen y N. Hamada. 2015. Analysis of urban impacts on aquatic hábitats in the central Amazon basin: adultes odonates as bioindicators of enviromental quality. Ecological Indicators, 48: 303311. 
Moucha, J. 1962. On Lepidoptera on Czechoslovak postage stamps. Journal of the Lepidopterists' Society, 16(2): 145-146.

Palacios-Vargas, J.G. 2011. Entomofilatelia: las estampillas postales con insectos y otros artrópodos en el mundo. (pp. 15-16). En: Navarrete-Heredia J.L., G. Castaño-Meneses, y G.A. Quiroz-Rocha (Eds.). Facetas de la Ciencia: Ensayos sobre Entomología Cultural. Universidad de Guadalajara.

Palacios-Vargas, J.G. y J.L. Navarrete-Heredia. 2002. Entomofilatelia, un aspecto de la entomología cultural. (pp.107-115). En: Llorente, J. y J.J. Morrone (Eds.). Biodiversidad, Taxonomía y Biogeografía de Artrópodos de México: Hacia una síntesis de su conocimiento. UNAM.

Pollock, D. 2000. Insects on stamps -good guys and bad guys-. Newsletter, The Entomological Society of Manitoba, 27(2): 1-14.

Reyes, E. y R. Núñez. 2008. La entomología en la filatelia cubana. Boletín Sociedad Entomológica Aragonesa, 43: 459-462.

Recibido: 20 de junio 2019

Aceptado: 9 de agosto 2019
Smith, M.E. 1954. Philatelic Lepidoptera. The Lepidopterists'News, 8: 13-16.

Torralba Burriall, A y F.J. Ocharan. 2007. Composición biogeográfica de la fauna de libélulas (Odonata) de la Península Ibérica, con especial referencia a la aragonesa. Boletín Sociedad Entomológica Aragonesa, 41: 179-188.

Turienzo, P. 2018. La enseñanza de la entomología mediante sellos postales como recurso didáctico. IDESIA, 36(3): 119-129.

Turienzo, P. y W. Alves Carneiro. 2017. La enseñanza de la biodiversidad por medio de la filatelia: el caso de la Argentina. I Congreso Provincial de Enseñanza de las Ciencias Naturales.

von Ellenrieder, N. 2009. Mecistogaster ornata. The IUCN Red List of Threatened Species 2009: e. T158808A5276319. Disponible en: http://dx.doi. org/10.2305/IUCN.UK.2009. Fecha de consulta: 17 de noviembre de 2018.

Welker, C.A.D. 2010. A filatelia como forma de divulgação da flora brasileira. Revista Brasileira de Biociências, 8(3): 273-278.

Zagkotas, V. y G. Niaoustas. 2019. Philately as a teaching aid through the implementation of a small-scale project in a Greek primary school. Education, 3(13): 1-10. 